\title{
Psychiatric disorders among patients presenting with attempted suicide in RIMS hospital, Manipur
}

\author{
Nandi Kaushik', Singh $S^{2}$, Bihari Thingbaijam ${ }^{3}$, Haobijam Asheema ${ }^{4}$ \\ Received on November 03, 2019; editorial approval on January 10, 2020
}

\begin{abstract}
Introduction: Suicide is fatal act that represents the person's wish to die. A suicide attempt is a self-initiated sequence of behaviors by an individual who, at the time of initiation, expected that the set of actions would lead to his or her own death. During the past decade, there have been dramatic and disturbing increases in reports of suicide among youths. Materials and methods: A cross-sectional study over a period of one year time was undertaken. All consecutive patients of both sexes aged 18-65 years who have attempted suicide attending Department of Psychiatry, RIMS, Imphal were taken. Results: A total of 45 patients were taken up. Among them 26 (57.8\%) were male and 19 (42.2\%) were female. Majority of them were below 30 years of age (55.6\%). $80 \%$ of the patients were diagnosed to have a psychiatric disorder, mostly Depression (44.4\%) followed by Schizophrenia (15.6\%). Conclusion: Considerable number of attempters suffered from psychiatric disorder. Early diagnosis of the psychiatric disorders and supportive measures for various stressors would help in prevention of suicidal attempts.
\end{abstract}

Keywords: Mode of suicide; psychiatric morbidity, depression.

\section{INTRODUCTION}

The story of suicide is probably as old as that of man himself. Through the ages, suicide has variously been glorified, romanticized, bemoaned, and even condemned. The word 'suicide' was first used by the English author, Sir Thomas Browne in 1642 in his treatise 'Religio Medici'. The word originated from 'Sui' (of oneself) and 'Caedes' (murder). ${ }^{1}$

It is fatal act that represents the person's wish to die. There is a range, however, between thinking about suicide and acting it out. Some persons have ideas of suicide that they will never act on; some plan for days, weeks, or even years before acting; and others take their lives seemingly on impulse, without premeditation. ${ }^{2} \mathrm{~A}$ suicide attempt is a selfinitiated sequence of behaviors by an individual who, at the time of initiation, expected that the set of actions would lead to his or her own death. ${ }^{3}$

The risk of suicide is the most common life-threatening situation that mental health professionals encounter. Its assessment is based on both an understanding of its epidemiology, which alerts the clinician to potential danger, and the individualized assessment of the patient. During the past decade, there have been dramatic and disturbing increases in reports of suicide among youths. Understanding the risk factors can help dispel the myth that suicide is a random act or result from stress alone. Many suicidal individuals want to live, but they are unable to see the alternatives, an issue that should always be taken seriously when assessing the risk of suicide. ${ }^{4}$
Address of correspondence:
${ }^{1}$ Post Graduate Trainee
${ }^{2}$ Associate Professor (Corresponding author)
Department of Psychiatry
Mobile: +919862032931
Email:drgojendra@gmail.com
${ }^{3}$ Professor
${ }^{4}$ Senior Resident
Department of Psychiatry
Regional Institute of Medical Sciences (RIMS), Imphal. 
Suicide is a complex, multidimensional phenomenon that has been studied from philosophical, sociological and clinical perspective; a student kills himself to escape the ignominy of exam failure; a woman burns herself to escape daily harassment by in-laws over inadequate dowry; finance dealer ends his life to fend off the horde of creditors. ${ }^{5}$ Suicide has grown as a silent epidemic, resulting in psychological distress $\&$ financial burden among the relatives of the victims at the family level, as well as great economic problems for the whole society in a statistical sense. ${ }^{6}$

Every year close to $8,00,000$ people take their own life and there are many more people who attempt suicide. Every suicide is a tragedy that affects families, communities and entire countries and has long-lasting effects on the people left behind. For every suicide, there are many more people who attempt suicide every year. A prior suicide attempt is the single most important risk factor for suicide in the general population. Suicide is the second leading cause of death among 15-29 year-olds. Out of 8,00,000 people committing suicide worldwide every year, of these 1,35,000 $(17 \%)$ are residents of India. ${ }^{7}$

The rates of suicide have greatly increased among youth, and youth are now the group at highest risk in one third of the developed and developing countries. The emerging phenomenon of 'cyber suicide' in the internet era is a further cause for concern; also because the use of new methods of suicide are associated with epidemic increases in overall suicide rates. ${ }^{1}$

It is very clear that suicide is one of the greatest challenges that our generation is facing. The youth are most vulnerable to suicidal ideations and attempted suicide. So, it is the need of the hour to understand and study the impact of various types of psychiatric illness among the attempted suicide patients. This will help us in proper evaluation and management of psychiatric disorders and prevent the act of suicide and hence the study has been undertaken.

This paper has aimed to determine the socio-demographic profile and psychiatric disorders in patients presenting with attempted suicide in department of psychiatry, RIMS

\section{MATERIALS AND METHODS:}

- Study design: Cross-sectional study

- Set up: Department of Psychiatry, RIMS, Imphal

- Duration of Study: August 2017 to July 2018

- Study population: Within a period of one year time, all consecutive patients of both sexes aged 18-65 years who have attempted suicide attending Department of Psychiatry, RIMS were be taken up for the study

- Study tools: Semi-structured questionnaires for recording the socio-demographic information and Mini
International Neuropsychiatric Interview Plus (M.I.N.I Plus 5.0.0) for assessment of psychiatric co-morbidities. ${ }^{8}$

The patients and caregivers were interviewed using semistructured questionnaires to record the socio-demographic data and clinical history followed by a detailed mental status examination. Privacy during interview and client confidentiality was maintained.

\section{RESULTS}

A total of 45 patients presenting with attempted suicide were taken up in this study. Among them 26 (57.8\%) were male and $19(42.2 \%)$ were female. 22 were married, 21 unmarried and 2 were widow/widower.

Out of the study population maximum patients (35.6\%) were in the age group of 21-30 years followed by 31-40 years group $(26.7 \%)$. However a total of $55.6 \%$ were within the age of 30 years as shown in Table 1. A total of $62.2 \%$ of patients were educated till matriculate or below. $22.2 \%$ were higher secondary pass and only $15.5 \%$ were graduate and above [Table 2]. Among the suicide attempters maximum $(31.1 \%)$ were unemployed, followed by students (24.4\%) as shown in Table 3.

Table 4 shows that $80 \%$ of the patients were diagnosed to have a psychiatric disorder, mostly Depression (44.4\%) followed by Schizophrenia (15.6\%) and Alcohol dependence (8.9\%). 20\% did not fulfill any diagnostic criteria. Maximum (55.6\%) patients tried to commit suicide by means of Poisoning, followed by Hanging $(24.4 \%)$ as shown in Table 5. Maximum $(75.6 \%)$ patients were first time attempters, while $13.3 \%$ of them had one prior history of suicidal attempt as shown in Table 6.

Table 1 Age Distribution

\begin{tabular}{|l|c|c|}
\hline Age in years & No. of patients & \% \\
\hline $18-20$ & 9 & 20.0 \\
\hline $21-30$ & 16 & 35.6 \\
\hline $31-40$ & 12 & 26.7 \\
\hline $41-50$ & 5 & 11.1 \\
\hline $51-60$ & 3 & 6.7 \\
\hline Total & $\mathbf{4 5}$ & $\mathbf{1 0 0 . 0}$ \\
\hline
\end{tabular}

Table 2 Educational Status

\begin{tabular}{|l|c|c|}
\hline Education & No. of patients & \% \\
\hline Illiterate & 2 & 4.4 \\
\hline Middle education & 8 & 17.8 \\
\hline Matriculate & 18 & 40.0 \\
\hline Higher secondary & 10 & 22.2 \\
\hline Graduate & 5 & 11.1 \\
\hline Post graduate & 2 & 4.4 \\
\hline Total & $\mathbf{4 5}$ & $\mathbf{1 0 0 . 0}$ \\
\hline
\end{tabular}


Table 3 Employment Status

\begin{tabular}{|l|c|c|}
\hline Employment status & No. of patients & \% \\
\hline Unemployed & 14 & 31.1 \\
\hline Govt. job & 4 & 8.9 \\
\hline Self employed & 10 & 22.2 \\
\hline Student & 11 & 24.4 \\
\hline Housewife & 6 & 13.3 \\
\hline Total & $\mathbf{4 5}$ & $\mathbf{1 0 0 . 0}$ \\
\hline
\end{tabular}

Table 4 Diagnosis

\begin{tabular}{|l|c|c|}
\hline Diagnosis & $\begin{array}{c}\text { No. of patients } \\
(\mathbf{n = ~ 4 5 )}\end{array}$ & $\mathbf{\%}$ \\
\hline No Diagnosis & 9 & 20.0 \\
\hline Diagnosis & $\mathbf{3 6}$ & $\mathbf{8 0 . 0}$ \\
\hline - Depression & 20 & 44.4 \\
\hline - Schizophrenia & 7 & 15.6 \\
\hline - Alcohol Dependence & 4 & 8.9 \\
\hline - Opioid Dependence & 2 & 4.4 \\
\hline - Cannabis dependence & 1 & 2.2 \\
\hline - BPAD & 1 & 2.2 \\
\hline - Anxiety disorder & 1 & 2.2 \\
\hline
\end{tabular}

Table 5 Mode of suicide attempt

\begin{tabular}{|l|c|c|}
\hline Mode of Suicide & No. of patients & \% \\
\hline Hanging & 11 & 24.4 \\
\hline Poisoning & 25 & 55.6 \\
\hline Cut throat & 3 & 6.7 \\
\hline Self-immolation & 1 & 2.2 \\
\hline Stabbing & 3 & 6.7 \\
\hline Others & 2 & 4.4 \\
\hline Total & $\mathbf{4 5}$ & $\mathbf{1 0 0 . 0}$ \\
\hline
\end{tabular}

Table 6 Number of previous suicide attempt

\begin{tabular}{|l|c|c|}
\hline No of previous Attempts & No. of patients & \% \\
\hline 0 & 34 & 75.6 \\
\hline 1 & 6 & 13.3 \\
\hline 2 & 2 & 4.4 \\
\hline 3 & 2 & 4.4 \\
\hline 4 & 1 & 2.2 \\
\hline Total & $\mathbf{4 5}$ & $\mathbf{1 0 0 . 0}$ \\
\hline
\end{tabular}

\section{DISCUSSION}

45 patients who attempted suicide were taken up over the study period. Majority of them were below 30 years of age (55.6\%). Similar observations were made in most of the Indian studies. In a study conducted by Kodali $\mathrm{M}^{11}$ it was found that majority $(67 \%)$ of the suicide attempters were $<30$ years of age. This is also supported by another study by Nabi $\mathrm{J}^{10}$ where it was seen that majority of the suicide attempters (58\%) were of young age group (18-25 years). Male predominance was observed $(57.8 \%)$, which is consistent with the studies by Rao $\mathrm{KN}^{13}(52 \%)$ and also by Kodali $\mathrm{M}^{11}(67 \%)$. However a study by Nabi $\mathrm{J}^{10}$ showed female predominance (62\%).

Being separated or divorced was noted to be significantly associated with increased suicidal risk among western literatures (Hawton $\mathrm{K})^{12}$, however our study showed no such findings. Many Indian studies states that majority of the suicide attempters were married. Study by Nabi $\mathbf{J}^{10}$ found that 59\% suicide attempters were married. Similar findings were noted by Kodali $\mathrm{M}^{11}$ where $57 \%$ were married. $62.2 \%$ were educated till matriculation or below. Study by Rao $\mathrm{NK}^{13}$ states that $42.0 \%$ of the suicide attempters were class $\mathrm{X}$ pass or below.

$31.1 \%$ people were unemployed. A study by $\mathrm{Lin}^{\mathrm{C}^{14}}$ shows an unemployment rate of $51.0 \%$. Another Indian study by Karthik kumar $\mathrm{R}^{6}$ shows that $46 \%$ of suicide attempters were unemployed.

$80 \%$ of the patients were diagnosed to have a psychiatric disorder, mostly Depression (44.4\%) followed by Schizophrenia (15.6\%). $20 \%$ suicide attempters did not fulfill any diagnostic criteria and were mostly impulsive acts. Kodali $\mathrm{M}^{11}$ found in his study that $59 \%$ of suicide attempters suffered from a psychiatric disorder and major depressive episode $(28 \%)$ was found to be most common diagnosed disorders. Study by Pandey $\mathrm{AK}^{9}$ states that psychiatric morbidity was present in $60 \%$ of the cases and major depressive disorder was most common among them. The prevalence of psychiatric morbidity was as high as $89 \%$ in a study conducted by Rao $\mathrm{KN}^{13}$. Among them Mood disorders $(47 \%)$ were maximum and psychotic disorders were diagnosed in $11 \%$ of cases.

Mode of attempt was Poisoning (55.6\%) followed by Hanging $(24.4 \%)$. This finding is supported by various other Indian studies. Karthik kumar $\mathrm{R}^{6}$ conducted a study that showed that mode of suicide was poisoning in $83 \%$ of cases and hanging in $14 \%$. Study by Rao $\mathrm{KN}^{13}$ found that Majority (71\%) of the suicide attempters had resorted to consumption of chemical compounds. Insecticides were consumed by $52 \%$ in a study by Kodali $\mathrm{M}^{11}$.

No $75.6 \%$ patients were first time attempters. Kodali $\mathbf{M}^{11}$ found in his study that $76 \%$ of the suicide attempters did not have prior suicidal attempts. History of previous suicidal attempt in the past was present in only $18 \%$ of the cases as seen in a study by Nabi $\mathrm{J}^{10}$.

\section{CONCLUSION}

The study has several limitations. The Sample size is small and data on follow-up and treatment retention were not included. Even with the above limitations, this study served the purpose of treating the psychiatric morbidity in the 
study population. Thus, it can be concluded that considerable number of attempters suffered from psychiatric disorder. Early diagnosis of the psychiatric disorders and supportive measures for various stressors would help in prevention of suicidal attempts. Lack of restriction for procurement of poisons and easy availability may be the reason for the preference to use these agents for attempting suicide.

The results conclude that the variables enhancing the risk of suicide among the vulnerable groups if identified, it would effectively help in early detection and prevention of suicide attempts.

Thus, many Lives could be saved in time.

Acknowledgements: The authors are grateful to the Department of Psychiatry, RIMS for providing a platform for this study and also to the patients who enrolled, without whom this study would not have been possible.

\section{Conflict of interest: None.}

Contribution of authors: We declare that this work was done by the authors named in this article and all liabilities pertaining to claims relating to the content of this article will be borne by the authors.

\section{Ethical approval: Taken.}

\section{REFERENCES}

1. Radhakrishnan R, Andrade C. Suicide: An Indian perspective. Indian J of Psychiatry 2012;54(4):304-19.

2. Sadock BJ, Sadock VA. Kaplan and Sadock's Synopsis of Psychiatry. 10 ${ }^{\text {th }}$ ed. New York: Lippincott and Williams; 2007.

3. American Psychiatric Association, Diagnostic and Statistical Manual of Mental Disorders. $5^{\text {th }}$ ed. Washington DC: New School Library; 2013.

4. Tasman A, Kay J, Lieberman JA, First MB, Riba MB. Psychiatry. $4^{\text {th }}$ ed. West Sussex: John Wiley \& Sons Ltd; 2015.

5. Ghanate A, Deepak RS, Patil V, Surpur R, Anitha MR, Vijayanath V. Prevalence of Psychiatric Comorbidity in Suicide Attempters. Int J Curr Microbiol App Sci 2013;2(1):100-5.
6. Karthikkumar R, Asok MK, Gandhibabu R, Vinoth D. A study of Psychiatric comorbidities in Adult who Attempted Suicide. Int J Mod Res Revs 2015 Oct 24;3(10):914-8.

7. World Health Organization. Suicide; 2017; [about 1 screen]. Available at: http://www.who.int/mediacentre/ factsheets/fs398/en/ Assessed July 24, 2017.

8. Sheehan DV, Lecrubier Y, Sheehan KH, Amorim P, Janavs J, Weiller E, et al. The Mini-International Neuropsychiatric Interview (M.I.N.I.): the development and validation of a structured diagnostic psychiatric interview for DSM-IV and ICD-10. J Clin Psychiatry 1998;59(20):22-33.

9. Pandey AK, Singh H, Dalal PK, Tripathi A, Dutt K, Sinha PK. Psychiatric Morbidity in Suicide attempters attending University Hospital of North India. Delhi Psychiatry Journal 2013;16(1):71-7.

10. Nabi J, Ghildiyal R, Mir MS, Zaffer N, Kaur D, Suhaff AA. Psychiatric Co-Morbidity in Patients with Attempted Suicide- A Hospital Based Study. J Med Sci Clin Res 2016 Oct;4(10):13409-16.

11. Kodali M, Kilaru K. Psychiatric Morbidity of Attempted Suicide Patients admitted to a General Hospital in Rural area of South India. IOSR Journal of Dental and Medical Sciences 2013 Jan;4(3):46-50.

12. Hawton K, Houston K, Haw C, Townsend E, Harriss L. Comorbidity of Axis I and Axis II Disorders in Patients who Attempted Suicide. Am J Psychiatry 2003 Aug;160(8):1494-500.

13. Rao NK, Kulkarni RR, Begum S. Comorbidity of Psychiatric and Personality Disorders in First Suicide Attempters. Asian J Psychiatry 2013 Oct;6(5):410-6.

14. Lin C, Yen T, Juang Y, Lin J, Lee S. Psychiatric Comorbidity and Its Impact on Mortality in Patients Who Attempted Suicide by Paraquat Poisoning during 2000-2010. Taiwanese J Psychiatry 2014 Nov; 9(11):112-9. 